\title{
Hepatocellular Carcinoma in Port Harcourt, Nigeria: Clinicopathologic Study of 75 Cases
}

\author{
${ }^{1}$ D. Seleye-Fubara and ${ }^{2}$ N. J. Jebbin \\ Departments of ${ }^{1}$ Pathology and ${ }^{2}$ Surgery, University of Port Harcourt Teaching Hospital, Port Harcourt, Nigeria \\ Reprint requests to: Dr. D. Seleye-Fubara, Department of Pathology, University of Port Harcourt Teaching \\ Hospital, P. M. B. 6173, Port Harcourt, Nigeria.E-mail: dsfubara@yahoo.com
}

\begin{abstract}
Background: Hepatocellular carcinoma (HCC) is a complication of liver cirrhosis caused by hepatitis B viral infection, fungal infection and genetic factors. This disease though having a silent course is associated with variable morbidity and mortality in this environment.

Methods: Previously prepared histologic slides were retrieved and re-evaluated to confirm the diagnosis. Clinical data such as the age, sex, clinical presentations, histologic grading and cause of death were extracted from the case notes, histology request forms and autopsy protocol forms.

Results: Seventy five cases were used for the study during the period under review. The youngest was a 14 year old male while the oldest was a 66 years old male. Male to female ratio was 2:1. Majority (28\%) occurred in the age group 40-49 years. Upper abdominal mass was the most common clinical presentation (30.7\%) and well differentiated hepatocellular carcinoma was the most common (64.0\%) histologic grade. Trabecular / sinusoidal pattern (49.3\%) was the most common histologic type (pattern) while upper gastro-intestinal bleeding (38.7\%) was the most common cause of death at autopsy.

Conclusion: Hepatocellular carcinoma is a notable malignancy of the liver associated with variable morbidities and mortality as it has an insidious onset and very aggressive course.
\end{abstract}

Key words: Hepatocellular carcinoma, trabecular pattern, cirrhosis, hepatitis B Virus

\begin{abstract}
Résumé
Introduction: Carcinome Hépatocellulaire est une complication de la cirrhose causée par l'infection d'Hépatite B virale, mycose, et des facteurs génétiques. Cette maladie quioque sa cause est taciturne est liée avec un variable ayant rapport à la morbidité et la mortalité dans ce milieu.

Méthode: Des plaques histologique préparées auparavant ont été récuperées et évaluées de nouveau afin de confirmer des données cliniques diagnostiques telles que l'âge, sexe, présentation cliniques, classement histologique et la cause de la mort ont été tirés du dossier médical, formulaire du demande histologique, et des formulaires des protocole d'autopsie.

Résultats: Soixante quinze cas ont été utilisés pour l'étude au cours de la période de cette étude. Le plus jeune est du sexe masculin âgé de 14 ans tandis que le plus âgé est hun homme âgé de 66 ans. Propotrtion sexe masculin et sexe féminin était $2: 1$. La majorité $28 \%$ arrive chez la tranche d'âge de 40 49 ans. Masse abdominale supérieure était la présentation clinique la plus ordinaire $(30,7 \%)$ et le carcinome hépatocellulaire bien déterminé était le plus ordinaire $(64,0 \%)$ classement histologique. La tendance trabeculaire/sinusoidale $(49,3 \%)$ était le type (tendance) histologique le plus ordinaire tandis que saigant gastro-intestinal supérieur $(38,7 \%)$ était la cause de la mort la plus ordinaire pendant l'autopsie.

Conclusion: Carcinome Hépatocellulaire est une malignité remarquable du la foie liée avec des variables de la morbidité et de la mortalité parcequ'il a un debut insidieux et une évolution très aggressive.
\end{abstract}

Mots-clés: Carcinome hépatocellulaire, tendance trabéculaire, la cirrhose hépatite B virus

\section{Introduction}

Hepatocellular carcinoma (HCC) is one of the world's foremost solid malignancies, causing approximately one million death yearly. ${ }^{1}$ This cancer has a heterogeneous geographical distribution based on the prevalence of risk factors in different parts of the world. It is frequent in the sub-Saharan Africa and 
South East Asia where it is responsible for a large proportion of cancer deaths but is rare in USA and Europe. ${ }^{2}$ The high incidence rate may be related to the high prevalence of Hepatitis B viral (HBV) infection, aflatoxin $\mathrm{B}_{1}$ contamination and some hepatotoxic drugs. ${ }^{3,4}$ Hepatitis $\mathrm{C}$ virus (HCV), cigarette smoking and alcohol are also etiologic agents in this environment. ${ }^{5}$ Recently, there is an upsurge of HCC in United States due to increased HCV infection. ${ }^{6}$

The transformation of hepatocytes to the malignant phenotype may occur irrespective of the etiological agents. In the context of increased cellular turnover induced by chronic liver injury and regeneration, the activation of cellular oncogenes or the inactivation of tumor suppressor gene are the common denominators contributing to the development of HCC. ${ }^{7}$ The oncogenic mechanism of $\mathrm{HBV}$ is thought to be based on genetic damage associated with chronic inflammation and the integration of HBV DNA into the host genome. ${ }^{8}$ Aflatoxin $B_{1}$ has been shown to induce mutations at codon 249 of the P53 tumor suppressor gene thus providing a clue to how an environmental factor may contribute to tumor development at molecular level. ${ }^{7,9}$ $\mathrm{HCC}$ is an asymptomatic and slow growing malignancy whose natural history is an extension of underlying cirrhosis. ${ }^{8}$ This tumor is aggressive in blacks ${ }^{10}$ and associated with poor prognosis. ${ }^{10,11}$

This is a report of HCC histologically diagnosed at the University of Port Harcourt Teaching Hospital (UPTH) with respect to age, sex, clinical presentation, and cause of death, as well as histological grading and types in this environment.

\section{Materials and Methods}

All the surgical biopsies (incisional biopsies and autopsy specimens) of the liver cancer received in the University of Port Harcourt Teaching Hospital, Port Harcourt, Nigeria, which were diagnosed and confirmed as hepatocellular carcinoma by the authors, were used for the study. These tissues were histologically processed and stained with haematoxylin and eosin stains. Cases with incomplete documentation, fine needle aspiration, and ascites fluid cytology specimen were excluded from the study. The age, sex, clinical presentation and the type of biopsies were extracted from the request forms, clinical records and autopsy reports. The results have been analyzed.

\section{Results}

A total of 2105 malignancies were diagnosed during the study period, January 1990 - December 2001. Out of these, 81 tissues were primary liver cell carcinoma which accounted for $3.8 \%$ of the total malignancies. One of the malignant tumours was a cholangiocarcinoma and five were diagnosed by ascitic fluid and fine needle aspiration cytology, these were excluded from the study. This study is therefore based on 75 hepatocellular carcinoma representing $3.6 \%$ of the total malignancies.

The age and sex distribution of HCC is shown in table 1 . The youngest was a 14 year old male and the oldest was a 66 year old male with a mean age of 42 years. The highest frequency occurred in the age group $40-49$ years $(28.0 \%)$. On the whole, $66.7 \%$ of cases occurred in males and $33.3 \%$ in females giving a sex ratio of $2: 1$. Sixty two $(83 \%)$ were autopsy specimens while only $13(17 \%)$ were surgical biopsies.

Table 2 shows the clinical presentations of patients. The most common presentations in order of decreasing frequency are upper abdominal mass $23(30.7 \%)$, right hypochondrial pain $16(21.3 \%)$, ascites 12(16\%) while massive gastrointestinal bleeding 10(13.3\%); weight loss, jaundice, hypoglycemia and polycythaemia accounted for $6(8.0 \%), 4(5.3 \%), 3(4.0 \%)$ and $1(1.3 \%)$ respectively.

The various histologic grades of the cancer are presented in table 3, of which well differentiated HCC accounted for 48(64.0\%), anaplastic HCC 20(26.7\%) and moderately differentiated $\mathrm{HCC} 7(9.3 \%)$. The histological types were trabecullar/sinusoidal pattern $37(49.3 \%)$, pseudogalndular/acinar pattern $21(28 \%)$, compact pattern $12(16.0 \%)$, clear cell $3(4.0 \%)$, scirrhous/fibrolamella $2(2.7 \%)$.

The cause of death in the $62(82.7 \%)$ of the cases that had autopsy were, upper gastro-intestinal hemorrhage (variceal bleeding) 24(38.7\%), liver failure 18 (29\%), intratumour hemorrhage 14 (22.6\%) and intraperitoneal hemorrhage $6(9.7 \%)$.

Table 1: Age and sex of 75 cases of hepatocellular carcinoma

\begin{tabular}{llll}
\hline Age (years) & M & F & Total $(\%)$ \\
\hline$<20$ & 5 & 3 & $8(10.7)$ \\
$20-29$ & 2 & 4 & $6(8.0)$ \\
$30-39$ & 12 & 6 & $18(24.0)$ \\
$40-49$ & 16 & 5 & $21(28.0)$ \\
$50-59$ & 10 & 4 & $14(18.7)$ \\
$\geq 60$ & 5 & 3 & $8(10.7)$ \\
\hline Total $(\%)$ & $50(66.7)$ & $25(33.3)$ & $75(100)$ \\
\hline
\end{tabular}

Table 2: Clinical presentation in 75 patients with hepatocellular carcinoma

\begin{tabular}{ll}
\hline Clinical presentation & No. (\%) \\
\hline Upper abdominal mass & $23(30.7)$ \\
Right hypochondrial pain & $16(21.3)$ \\
Ascites with generalized abdominal & $12(16.0)$ \\
pain & \\
Massive gastrointestinal hemorrhage & $10(13.3)$ \\
Weight loss only & $6(8.0)$ \\
Jaundice with weight loss & $4(5.3)$ \\
Hypoglycemia & $3(4.0)$ \\
Polycythaemia & $1(1.3)$ \\
\hline Total & $75(100)$ \\
\hline
\end{tabular}


Table 3: Histological grade and type of 75 cases of hepatocellular carcinoma

\begin{tabular}{ll}
\hline Histology & No. (\%) \\
\hline Grade & \\
Well differentiated & $48(64.0)$ \\
Moderately differentiated & $7(9.3)$ \\
Anaplastic & $20(26.7)$ \\
Type & \\
Trabecular /sinusoidal pattern & $37(9.3)$ \\
Pseudoglandular/acinar pattern & $21(28.0)$ \\
Compact pattern & $12(16.0)$ \\
Clear cell pattern & $3(4.0)$ \\
Scirrous/fibrolamella pattern & $2(2.7)$ \\
\hline
\end{tabular}

\section{Discussion}

Hepatocellular carcinoma (HCC) is notorious for its insidious onset and silent course which renders early diagnosis extremely difficult. Biopsies for histological diagnosis were obtained from autopsies, and incisional biopsies in different proportions. Those obtained by ascitic fluid and fine needle aspiration cytology were excluded from the study because they cannot be histologically typed. The cancer predominantly occurred in males with a sex ratio of $2: 1$ in their fourth and fifth decades of age. This finding is similar to the 2:1 male dominance recorded in other studies but varied with the $30-40$ years peak age. ${ }^{4,5,11,12}$ In another study the tumor occurs $4-6$ times more in males than females with a peak at $5^{\text {th }}$ $6^{\text {th }}$ decades of age. ${ }^{13}$

Hepatitis B viral (HBV) infection is the most common etiologic agent as most of the patients presented with liver cirrhosis. This infection is contracted mainly through administration of blood and blood products from individuals with active disease or carriers. The transfer may occur through shared needle mainly among intravenous drug abusers, during sexual intercourse, accidental spillage of blood specimen in the laboratory and transfusion of blood products. ${ }^{14}$ A study in western Nigeria on primary liver cell cancer showed that, majority of the patients had scarification marks and injections from quack doctors which must have predisposed them to HBV infection and subsequent liver cirrhosis. ${ }^{12}$

Mycotoxins such as aflatoxin B, produced by the fungus Aspergillus flavus is equally an important etiologic agent in this environment. ${ }^{7,11,12}$ This can also be acquired by the consumption of stale nuts, grains and bread which is common among the low socio economic class ${ }^{11}$. The aflatoxin $\mathrm{B} 1$ is known to be associated with mutation, the genome of hepatocytes by inducing mutation at codon 249 of P53 tumor suppressor gene. 7,9 The HBV and aflatoxin B1 as the foremost etiologic agent is similar to the etiologic agents on other studies elsewhere. ${ }^{9,13}$

Herbal concoctions and different analgesic drugs are constantly abused in this part of the country for several disease conditions by alternative health practitioners. ${ }^{12}$ The hepatotoxicity of some of these herbs and drugs has been reported by other studies. ${ }^{12,15,16}$ The emphasis on the possibility of hepatotoxic herbs on the pathogenesis of HCC needs further elaborate study. Some studies recognized alcohol and cigarette smoking as an associated etiologic factor for the pathogenesis of HCC. ${ }^{7,8,12}$

Autopsy was performed in sixty three cases $(84.0 \%)$ of which sixteen $(21.33 \%)$ were clinical autopsies performed on the authority of the deceased relations for death certification or by the hospital for confirmation of clinical diagnosis and treatment. The other forty seven cases $(62.67 \%)$ were those that died suddenly whose autopsies were requested by the coroner. The clinical autopsy rate compares favorably with the $22.6 \%$ cases reported in another local study in Western Nigeria. ${ }^{12}$ In each cases a thorough autopsy following standard procedures was performed. Metastatic lesions to the lungs was found in forty $(53.3 \%)$ cases; mirroring the $53.3 \%$ cases recorded in earlier studies in this country. ${ }^{11.17}$ All the autopsied cases were associated with either macronodular or mixed nodular cirrhosis. This is not surprising because, HCC is a primary complication of liver cirrhosis. The disease (HCC) is also associated with serosanguinous ascitic fluid. The cause of death was either hemorrhagic shock from variceal bleeding, hepatic failure, intraperitoneal bleeding and intra tumor hemorrhage. This view is at variance with another local study where liver failure was the leading cause of death. ${ }^{12}$

The whole tissue biopsies histologically showed well differentiated $\mathrm{HCC}$ as the most common grade $(64.0 \%)$ of all the cases while the anaplastic grade represents $26.67 \%$ cases. These high values may be attributed to the sample size. The most common histologic variant was the trabecular pattern which accounted for $49.33 \%$ of cases in this study.

Most of the tumors were seen in an advanced stage and the striking aggressiveness of these tumours is similar to those reported in other African ${ }^{3,6}$ and local studies especially during pregnancy and lactation $^{18}$. The tumors clinically present as large solitary nodules, multiple nodules and diffused pattern in valuable proportions. Three $(4 \%)$ of our cases presented with hypoglycemia and one with polycythaemia. These are perhaps the paraneoplastic syndrome associated with the disease. Most of our patients presented with abdominal mass, right hypochondrial pains and ascites. Weight loss, massive gastrointestinal bleeding and frank jaundice are rare presentation in this study.

This cancer is ill-responsive to chemotherapy and radiotherapy. Perhaps the only method of effective treatment available is surgical resection of the tumor from the rest of the liver tissue and since our patients often present very late or when the tumor is in advanced stage, the prognosis is very bleak. Liver transplantation has been done for liver tumors in the United States and Britain ${ }^{19}$ but the long term results are disappointing. The option is only considered where there is no evidence of extrahepatic metastases meaning those patients with a localized tumor and without marked liver cirrhosis in the remaining hepatic lobes. Thus partial hepatectomy is the main 
operation performed in this environment and is usually carries high mortality. ${ }^{19}$

Hepatocellular carcinoma is a relatively common malignancy in this environment. It is associated with hepatitis $\mathrm{B}$ viral infection and subsequent liver cirrhosis, high intake of aflatoxin and hepatotoxic drugs abuse. It has an insidious onset, causing remarkable morbidity and mortality.

\section{References}

1. Munoz N, Bosch X. Epidemiology of hepatocellular carcinoma. In: Okuda K, Ishak KG (eds). Neoplasms of the liver. Springer, Tokyo, 1987;3-19

2. El-Domeiri AA, Huvos AG, Goldsmith HS, Foote FW. Primary malignant tumors of the liver. Cancer 1971; 27:7-11

3. Van-Rensburg SJ, Cook-mazaffari P, Van Schalkwyrk, DJ, VanDerwatt JJ, Vincent TJ, Purshase IF. Hepatocellular carcinoma and dietary aflatoxin in Mozambique and Transkei. Br J Cancer 1985; 51:713-726

4. Beasley RP, Hwang LY, Lin CC, Chien CS, Hepatocellular carcinoma and HBV a prospective study of 22707 men in Taiwan. Lancet 1981; 2:1129-1133

5. Olubuyide IO, Bamgboye EA. A case-control study of the current role of cigarette smoking and alcohol consumption in primary liver cell carcinoma in Nigerians. Afr J Med Sci 1990; 19:191-194

6. El-serag HB, Mason AC. Rising incidence of HCC in USA. N Engl J Med 1999; 340: 745-750

7. Moradpour D, Wands JR. The molecular pathogenesis of hepatocellular carcinoma. Journal of Viral Hepatitis 1994; 1:17-31

8. Okuda K. Hepatocellular carcinoma: recent progress. Hepatology 1992; 15: 948 - 963

9. Akriviadis EA, Llovet JM, Efremidis SC, et al. Hepatocellular carcinoma. Br J Surg 1998; 85: 1319-1331

10. Colombo M. Hepatocellular carcinoma in cirrhosis. Sem Liver Dis 1993; 13: 374-381

11. Francis TI, Smith JA. Hepatocellular carcinoma in Nigerians: a study of 144 autopsy proven cases (1958-1968). West Afr Med J 1972; 21: 37-42

12. Ndububa DA, Ojo OS, Adeodu OO, et al. Primary hepatocellular carcinoma in Ile-Ife, Nigeria. A prospective study of 154 cases. Niger J Med 2001; 10: 59-63

13. Mahan H. The liver, biliary tract and exocrine pancreas. In: Textbook of pathology. Jaypee Bros, New Delhi, 2000; 616-618

14. Chandrasoma P, Taylor CR. The liver: structure and function, infections. In: Concise pathology. McGraw-Hill, New York 1998; 630-648

15. MacGregor FB, Abernethy VE, Dahabra S, Cobden I, Hayes PC. Hepatotoxity of herbal remedies. Br Med J 1989; 299: 1156-1157

16. Tsega E. Hepatocellular carcinoma in Ethiopia: a prospective clinical study of 100 patients. East Afr Med J 1977; 54:281-291

17. Olubuyide IO. The natural history of primary liver cell carcinoma: a study of 89 untreated adult Nigerians. Central Afr J Med 1992; 38: 25-299

18. Ndububa DA, Makinde ON, Ojo OS, et al. Hepatocellular carcinoma in pregnancy and post partum period: a study of 6 cases in Nigerian women. Niger J Clin Pract 2004; 7: 46-49

19. Ongige-Leong $\mathrm{CH}$. Surgical treatment of primary liver cancer. J R Coll Surg Eding 1969;14: 42-55 